\title{
A survey of referrals to a special hospital (Rampton Hospital)
}

\author{
A.A. Close and E.P. Larkin
}

\begin{abstract}
The three special hospltals of England and Wales are provided for patients subject to detention on account of their dangerous, violent or criminal properties. Special hospltal psychiatrists cannot admit patients directly to hospltal - the psychiatrist's recommendations can be overturned by a local admissions panel. A two year retrospective study in Rampton Hosplital compared the outcomes of the psychiatrists' recommendations to admit or not to admit, with the decisions of the local admissions panel. There was complete agreement in over $90 \%$ of cases. This survey lends support to the view that special hospltal psychiatrists could admit pationts directly to hospital.
\end{abstract}

In 1989, the responsibility for managing the three special hospitals of England and Wales (Broadmoor Hospital, Ashworth Hospital and Rampton Hospital) moved from the Department of Health to a special health authority, the Special Hospital Services Authority (SHSA). Historically, referrals for admission to the special hospitals were decided by a multidisciplinary central admissions panel at the Department of Health in London. Following the introduction of the SHSA, local admissions panels were established for each special hospital to consider cases referred for admission.

In addition to the local admissions panels a central admissions panel (based at the SHSA) was set up:

(a) to monitor the operation of the local panels at each special hospital

(b) to consider difficult and sensitive admission applications which the local panels referred for advice or guidance.

The current procedure for admission to the hospital is as follows.

(a) Referrals to Rampton Hospital derive from the courts, Her Majesty's Prisons and NHS hospital including regional secure units. Such referrals may be to a named consultant on the staff of a hospital, but are usually directed towards the director of medical services or the hospital's unit general manager. (b) The referral is allocated to a special hospital consultant psychiatrist who visits the patient and prepares a psychiatric report. The report concludes with a recommendation for or against admission to Rampton Hospital.

(c) The local admissions panel considers the referral based upon the recommendations of the special hospital consultant psychiatrist and other relevant reports and information available. It makes its decision and offers a bed at this stage if the application is successful. The local admissions panel may override the recommendations made by the consultant psychiatrist. In certain circumstances, the local admissions panel will seek advice from the central admissions panel before making a decision.

(d) The central admissions panel may consider a rejected application and override the local admissions panel's decision to offer a bed. In some cases they may suggest that the local admissions panel reviews its decision.

(e) The Secretary of State at the Home Office retains statutory powers to direct the transfer of a prisoner to hospital (including a special hospital) or to recall a conditionally discharged patient to hospital. regardless of the views of the consultant. local admission panel, or central admissions panel.

The Report of the Committee of Inquiry into Complaints about Ashworth Hospital (1992) recommended that "medical staff should undertake an audit of the Admission Procedure and adopt a more forceful role in protecting the overall therapeutic aims of the establishment" (Recommendation 41). This review of the admission procedure at Rampton Hospital represents the first stage in such an audit.

\section{Objectives}

How do the recommendations made up by the consultant psychiatrist compare with the local 
AUDIT

Table 1. RMO recommendations and local admissions panel decisions in 'controversial' cases

\begin{tabular}{llrr}
\hline Consultant recommendation & Local admissions panel decision & No. & $\%$ \\
\hline Admit & Not admit & 13 & 50.0 \\
& Deferred decision - advice from central & 2 & 7.7 \\
admissions panel - not admit & 2 & 7.7 \\
& Deferred decision - advice from central & 2 & 3.9 \\
& admissions panel - admit & 1 & 3.9 \\
& Central admissions panel intervention - admit & 1 & 3.7 \\
Not admit & Admit Office intervention - admit & 2 & 1 \\
& Deferred decision - advice from central & & 3.9 \\
& admissions panel - admit & 4 & 15.4 \\
Total & Central admissions panel intervention - admit & 26 & 100.0 \\
\hline
\end{tabular}

admissions panel decisions? How often does the central admissions panel at the Special Hospital Services Authority (SHSA) intervene in decisionmaking and what form does this take? How often does the Home Office direct an admission or transfer of patients? What are the reasons give for differences in opinion? Are they based on clinical issues or on the grounds of perceived dangerousness (i.e. security issues)?

\section{The study}

Case files are kept on all referrals to Rampton hospital whether accepted for admission or rejected. Data were collected from this source for a retrospective survey of all referrals to Rampton Hospital during the two years from 1 January 1990 to 1 January 1992.

\section{Findings}

There were 353 referrals to Rampton Hospital for 316 patients during the sample period. Just over one third of these referrals (117) resulted in the offer of a bed. The vast majority of patients were referred once, one patient was referred four times.

Of all the referrals, 66 (19\%) cases were unable to be analysed further for the following reasons: in 38 cases the referral was simply for advice so the referral did not progress to the local admissions panel; 15 referrals were withdrawn by the referring agency; in six cases the patients were admitted as emergencies so no panel decision was taken upon them at the time; in four cases the patient was acquitted at court or sentenced to imprisonment; in two cases the patients were recalled to the hospital, having been conditionally discharged in the past and in one case the referral involved a transfer from another special hospital.
Of the 287 remaining referrals, 261 (91\%) were considered 'non-controversial' in so far as the consultant psychiatrist and the local admissions panel agreed on the recommendations for the patients. In 101 cases, the consultant psychiatrist and the local admissions panel agreed on admission for the patient. In 160 cases the consultant and the local admissions panel agreed on rejecting a referral for admission to the hospital.

The local admissions panel and the consultant psychiatrist disagreed on $26(9 \%)$ referrals corresponding to 24 patients. Table I shows how these decisions differed.

In five cases $(17 \%)$ the local admissions panel deferred a decision until advice had been sought from the central admissions panel. This advice was followed in all cases. In five cases the central admissions panel reviewed the decisions of the local admissions panel and intervened by advising that the decision not to offer a bed be reversed. In all but one of these cases, the consultant's recommendation was equally overturned. In one case, the Home Office intervened and directed the transfer of the patient. This occurred after the consultant psychiatrist had recommended admission, but both the local admissions panel and the central admissions panel had rejected the referral.

\section{Comment}

Differences in opinion fell into two main categories - clinical and security. Two thirds of the differences in opinion were for reasons of security.

Two main issues arose from the 'controversial' referrals. These were treatability and security. Although treatability was rarely in dispute, occasionally patients diagnosed with "psychopathic disorder' led to vigorous debate over whether or 
not a patient was 'treatable' and should be admitted to a special hospital. The degree of security required led to differences in opinion.

Special hospitals are provided for "Patients subject to detention who require treatment under conditions of special security on account of their dangerous, violent or criminal propensities" (NHS Act, 1977). In assessing a patient for admission to the hospital, special hospital consultant psychiatrists not only have to assess the nature of the mental disorder from which the patient is suffering, but also the degree of 'dangerousness' with which the patient presents. Predictions of dangerousness are fraught (Prins, 1986) and issues surrounding treatability in psychopathy have led to vigorous debate (Robertson, 1992).

In view of the fact that the local admissions panel consists of one medical member and three to four individuals from different professional backgrounds and that the panel deals with an average of three to four referrals weekly from a staff of up to ten consultant psychiatrists, it is not surprising that differences in opinion arose from time to time.

In the light of the 1992 Ashworth Inquiry's injunction that medical staff adopt a more forceful role in protecting the overall therapeutic aims of the establishment, it is reassuring to note that the opinions and recommendations of the consultant psychiatrists stood up well to independent multidisciplinary scrutiny. Few other medical procedures are subjected to such close scrutiny. It is of some interest that the admissions procedure for the only special hospital in Scotland, Carstairs Hospital, which also takes admissions from Northern Ireland, is markedly different from the three English special hospitals. In Carstairs Hospital, consultant psy- chiatrists on the staff of the hospital receive direct referrals from their consultant colleagues in the wider NHS. There is no local or central admissions panel.

Perhaps the results of this survey support a view that consultant psychiatrists working in Rampton Hospital could take direct admissions to hospital thereby reducing the bureaucracy and delays inherent in the local admissions procedure. Such a change could lead to a more sensitive and speedy response to patient need with the consequent development of closer working relationships with forensic colleagues and serving to further reduce the isolation and often perceived impenetrable barrier of the special hospitals. A change in the procedure allowing for direct admissions would be a fruitful area for clinical audit and the findings of this survey could serve as a useful baseline measure for such an audit.

\section{References}

NHS Act 1977. London: HMSO.

PRINS. H. (1986) Dangerous behaviour. In Dangerous Behavtour. the Law and Mental Disorder. London: Tavistock Publications.

Report of the Committee of Inquiry into Complaints about Ashworth Hospital (1992). London: HMSO.

ROBERTSON, G. (1992) Objections to the present system. Criminal Behaviour and Mental Health. 2, 114-123.

A. A. Close, Medical Audit Assistant, Rampton Hospital; and E. P. Larkin, Medical Audit Coordinator, Consultant Forensic Psychiatrist, Rampton Hospital, Retford, Nottinghamshire DN22 OPD

The views expressed in this article are not necessarily those of the Special Hospital Services Authority. 